\title{
Ecomuseo Bergslagen. un proyecto sueco de parque cultural
}

\author{
Ewa Bergdhal \\ Directora de Turismo Cultural del Consejo \\ Nacional de Patrimonio de Estocolmo \\ Directora del Ecomuseo Bergsladen (1996-1999)
}

Quisiera empezar mi presentación mostrando un pequeño resumen fotográfico de algunos de los cambios que han tenido lugar en Suecia durante los últimos 20 años. Es cada vez mayor el interés en el paisaje que en los lugares singulares. El interés se ha desplazado desde los lugares hacia las áreas.

Existe también, una conciencia creciente sobre la estrecha relación entre naturaleza y cultura. Cuando hacia finales de 1890 llega a Suecia el primer turismo masivo organizado, la naturaleza era tan interesante como la cultura y el viaje era una parte importante de la experiencia. Actualmente, estamos cada vez más acostumbrados a desplazamientos mayores, situación que resta interés a la experiencia antigua del desplazamiento. Cada vez es mayor la demanda de sensaciones más intensas cuando visitamos los lugares. La combinación de educación y entretenimiento ha influenciado la interpretación de lugares históricos en el paisaje.

Durante los últimos 5 años se ha incrementado en Suecia la colaboración a nivel nacional entre el Departamento de Medio Ambiente y el de Cultura. Se han desarrollado numerosos métodos de interpretación del patrimonio, así como iniciativas políticas orientadas a la mejora de las economías regional y local a través de difusión del patrimonio cultural; particularmente en aquellas regiones donde se han producido grandes cambios económicos.

En Suecia son diversas las áreas otrora industriales sometidas a procesos de pérdida de población, así como de la actividad industrial y comercial que las caracterizó. Un ejemplo ilustrativo es la región de Bergslagen, situada en la zona central. Se trata de un extenso territorio que se extiende desde la costa Este al Norte de Estocolmo, hasta la zona Oeste del país. Su ámbito central contiene grandes bosques con multitud de lagos y ríos que moldean un paisaje de suaves valles. Estos ríos discurren desde la zona Norte del país hacia el Sur donde se recogen en dos grandes lagos: Mälaren y Hjälmaren.

Se trata de una región rica en minerales como plata, cobre, hierro, etc. Su explotación practicada de forma regular por los habitantes desde la primera Edad Media, ha dejado grandes rastros sobre el paisaje. 
Pozos y minas perforan el suelo y dan acceso a un intrincado sistema de galerías subterráneas. La producción de hierro se ha extendido por un periodo de más de 800 años, hasta finales de 1980. Las condiciones para la producción de hierro fueron excelentes.

La región presentaba por tanto condiciones idóneas para el desarrollo de la industria. Disponía de capacidad para la obtención de minerales, bosques donde se extraían con gran facilidad grandes cantidades de carbón y unos ríos con caudal suficiente para producir energía. La conexión de estos con los lagos permitía el transporte fluvial de las materias primas con gran facilidad.

El Ecomouseo de Bergslagen nace a mediados de 1980 abarcando una región de 7.000 kilómetros cuadrados. Se trata del primer ecomuseo en Suecia. Su referencia más directa es el Ecomuseo francés de Le Creusot-Montceau-les-Mines. Éste se creó a partir de la revuelta de estudiantes de finales de 1960. Los museólogos franceses que lo diseñaron lo apodaron como "le musée eclaté", haciendo referencia a la explosión del museo. Era la expresión de la voluntad de llevar todas las actividades fuera del edificio tradicional del museo.

El trabajo con el patrimonio cultural se ha extendido sobre una extensa área donde numerosos sitios, monumentos y elementos paisajísticos locales fueron considerados parte de la propia exposición. Los lugares en el paisaje se transforman progresivamente desde espacios privados y delimitados, a espacios públicos reclamados por los residentes.

El término ecomuseo proviene del griego oikos, que significa posesión. Es el mismo prefijo que utilizamos para economía o ecología. El ecomuseo no tiene colecciones. Ésta sólo consiste en tierra, en la cual existen muchísimos rastros históricos y monumentos todavía visibles, que explican las actividades tradicionales de un pueblo en el territorio.

Es común la interpretación de los ecomuseos como lugares que tratan de temas ecológicos. Esto es cierto solo en parte, pues un ecomuseo se define no sólo por su contenido. Se reconoce fundamentalmente por su organización de grandes grupos de agentes con el objetivo común de fortalecer el desarrollo y la economía en una región concreta mediante la expresión de la identidad de sus habitantes locales.

El trabajo en el ecomuseo Bergslagen se inició con la elaboración de inventarios de la zona, financiado por dos estamentos regionales, y organizado como un proyecto de paisaje, cultura y patrimonio. Se organizó junto con los museos regionales de los condados de Dalarna y Västmanland y cerca de diez municipalidades se encargaron de los trabajos de campo. Los inventarios se presentaron en dos proyectos dife-
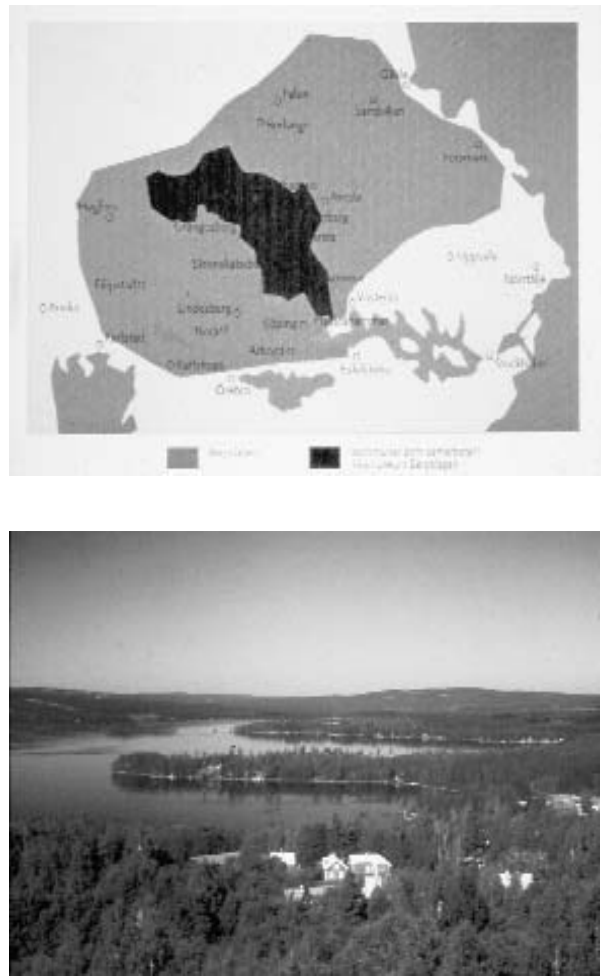
rentes que ya describian la idea de un ecomuseo.

Durante varios años las iniciativas políticas, tanto a nivel local como regional, se centraron en modificar las tendencias negativas del desarrollo de los distritos mineros. Entre 1960 y 1980 cerca de un 20\% de los habitantes perdieron sus trabajos y emigraron de la región. El desempleo aumentó rápidamente entre aquellos que se quedaron. Aumentaron también la inseguridad y los problemas sociales y los impuestos bajaron. Estas dos tendencias negativas se encontraron en un punto crítico.

La presentación de la idea de ecomuseo respondía a la necesidad de frenar la tendencia de involución de la región. Uno de los principales retos era cambiar la mentalidad de la población. Las minas y las fundiciones eran plantas con una organización tradicional muy fuerte. Utilizando la historia para reforzar la identidad local los políticos intentaron a su vez encontrar nuevas alternativas para la sociedad. El ecomuseo forzó asimismo la democracia social e involucró a la gente en un proceso de cambio social. Los visitantes formaban parte del proceso como participantes y los espacios se transformaban en lugares con eventos donde las cosas sucedían realmente.

El proceso estuvo encabezado por agentes públicos y la iniciativa privada no apareció hasta algunos años después, debido al crecimiento del turismo cultural.

Durante los primeros años de la década de los ochenta el proyecto estuvo en fase de rodaje. Los lugares se identificaban y registraban a la vez que numerosas iniciativas de protección y conservación se ponían en marcha. El trabajo empezó con la restauración de viejos edificios, pozos mineros, molinos de agua, plantas de fundición y viviendas. Se hicieron grandes esfuerzos para dotar a estos espacios de mayor accesibilidad para los visitantes. Cerca de cincuenta lugares se integraron en la red del ecomuseo, presentándose como lugares históricos.

El principal elemento en este paisaje cultural son las fundiciones de hierro, en todas las variantes producidas en el tiempo, así como las modificaciones en el paisaje cotidiano de las fundiciones. Los lugares de interés se escogieron en función de sus características históricas, así como de su capacidad para acoger cámpings, hoteles, restaurantes, tiendas de artesanía local, etc. Otro criterio importante fue la conexión con otros lugares notables de la región, así como el interés que suscitaba en los habitantes.

Tres años después de su puesta en marcha se inauguró una fundación donde los agentes públicos representaban la comisión directiva. También se estableció una comisión de asesoramiento que coordinaba un gran número de voluntarios. Esta comisión se encargaba a su vez del mantenimiento de los lugares
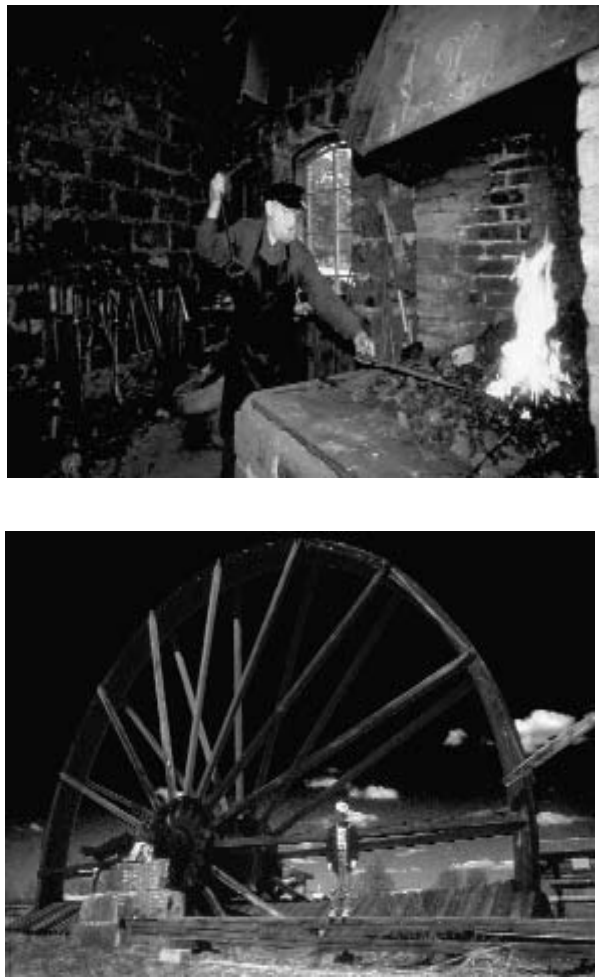
históricos locales, las actividades y las visitas guiadas. Un pequeño grupo formado por expertos museólogos asesoraba a los voluntarios en su trabajo.

La financiación de la organización se producía principalmente en forma de donativos por parte de las agencias públicas. A partir de 1996, con la entrada de Suecia en la Unión Europea, muchas de las actividades se han financiado con fondos estructurales europeos y mediante la participación en proyectos de cooperación internacional financiados por programas europeos.

El Ecomuseo Bergslagen tiene una gran oferta de actividades diferentes. Festivales, seminarios, grupos de estudio, viajes, programas especiales para niños y muchas oportunidades para probar tanto actividades tradicionales, como especialidades gastronómicas locales. El último año se alcanzó la cifra de un millón de visitantes.

El concepto de parque cultural ha ampliado su alcance con la creación del Ecomuseo Bergslagen.. El objetivo de su organización no es sólo el de preservar la historia de una región productora de hierro. Se trata de contribuir a un desarrollo económico positivo de la misma, objetivo poco usual para un museo, lo cual significa que está proyectándose más hacia el futuro de la región, que hacia su pasado.

Las imágenes que acompañan este texto explican el trayecto de Norte a Sur de la región. Se trata del mismo trayecto que los minerales seguían en su traslado desde las minas hasta las fundiciones y forjas.

Para acabar quisiera apuntar algunas ideas sobre las fases de desarrollo del museo y sus expectativas de futuro. Durante la primera etapa, desde su inauguración en 1986 hasta 1990, los trabajos se concentraron en la elaboración de inventarios y el reconocimiento de los diferentes lugares históricos. Este proceso se basó en la creación de una amplia y extensa red y en la consolidación y presentación del concepto del museo. Muchos agentes locales mostraron su interés durante este periodo y se sumaron al trabajo de desarrollar el acceso a los lugares históricos.

La siguiente etapa se concentró en lograr una organización fuerte, en fijar los objetivos, asegurar y fortalecer la economía y construir las rutinas diarias. Al mismo tiempo, se realizó mucho trabajo en la captación de voluntarios mediante la delegación de decisiones, fortaleciendo los aspectos democráticos.

La tercera etapa, entre 1996 y 2000, se caracteriza por posicionar el ecomuseo entre los museos tradicionales, así como por establecer relaciones con otras instituciones y programas a escala nacional e internacional. En esta etapa el ecomuseo ganó el galardón Michelletti y fue ganando importancia a nivel internacional.
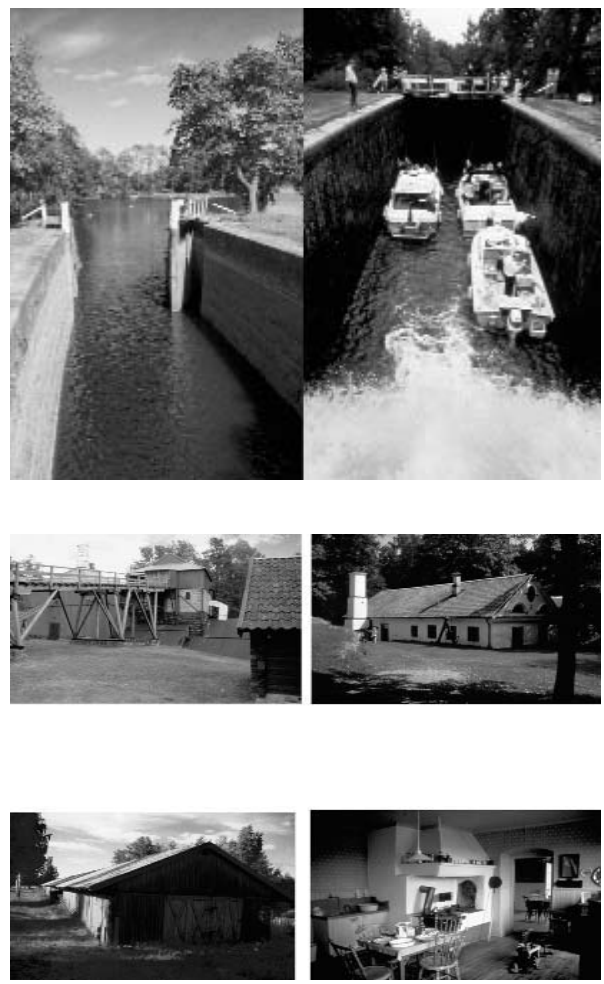
En los últimos años el trabajo en el ecomuseo se ha centrado en el desarrollo del turismo cultural en combinación con un extenso trabajo de colaboración con escuelas en el desarrollo de programas educacionales.

\section{¿Cuál es su futuro?}

Siete municipalidades locales y dos condados gestionan de manera conjunta la fundación, pero dado que la economía local en algunas de estas municipalidades presenta signos de debilidad existe, riesgo de quiebra de la organización. Esta puede producirse también si los políticos pierden el interés por desarrollar la región utilizando su patrimonio cultural.

El trabajo más importante en el futuro será fortalecer la red y aumentar la sensación de formar parte de un equipo entre todos los agentes involucrados. En la medida que la cooperación entre agencias turísticas y el ecomuseo se fortalezca, la discusión entre los métodos de preservación cultural y el desarrollo será posible. Si comparamos la situación actual con la existente hace 20 años veremos que en la actualidad la discusión se plantea en términos más constructivos. La pregunta que debemos formularnos es como podemos continuar manteniendo la calidad de estos lugares en el Parque Cultural con el aumento de visitantes.

Combinar los intereses de la preservación y los comerciales es crucial para el éxito y nuevos métodos se desarrollarán en el futuro. Pero lo que es aún más importante son las necesidades de crear y defender espacios públicos, donde la gente pueda encontrarse y comunicarse. Otra de las cuestiones importantes es trabajar en una perspectiva en cascada, pero desde abajo hacia arriba, lo que significa dar a los habitantes locales la oportunidad de convertirse en agentes activos, involucrados en los procesos de decisión.

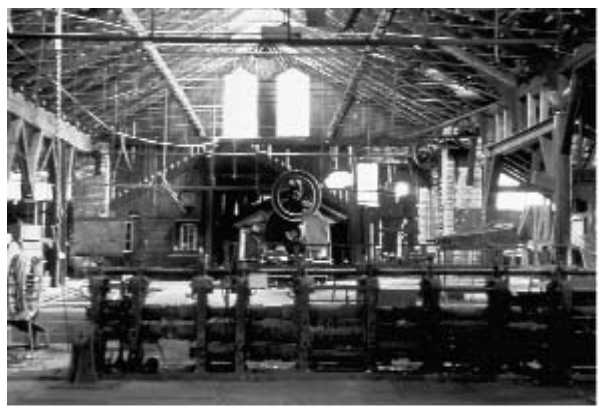




\title{
Paisaje cultural del café eb Brasil
}

\author{
André Munhoz de Argollo Ferrao \\ Docotr Arquitecto \\ Profesor de la Universidad Estatal de Campinas
}

\section{El patrimonio cultural representado por la arquitectura del café en Brasil}

La cadena productiva del café integra varios procesos, desarrollados en unidades físicas caracterizadas en el tiempo y el espacio por formas y funciones bien definidas destinadas a dar respuesta eficiente a las necesidades del conjunto, determinando una arquitectura específica y original de los edificios.

La evolucion técnica del proceso productivo del café en Brasil repercutió directamente en sus diversos subprocesos, exigiendo adaptaciones en el espacio destinado al desarrollo de distintas actividades, lo que implicó alteraciones formales y una correlación directa entre el desarrollo tecnológico y la evolución de la arquitectura propia del proceso de producción. En la medida que se introducían transformaciones en los programas productivos, éstas se reflejaban en el espacio requerido. En Brasil, esta relación entre "técnica y arquitectura" es explícita en el contexto de la cadena productiva del café, habiendo sido estudiada por autores de diversas disciplinas.1

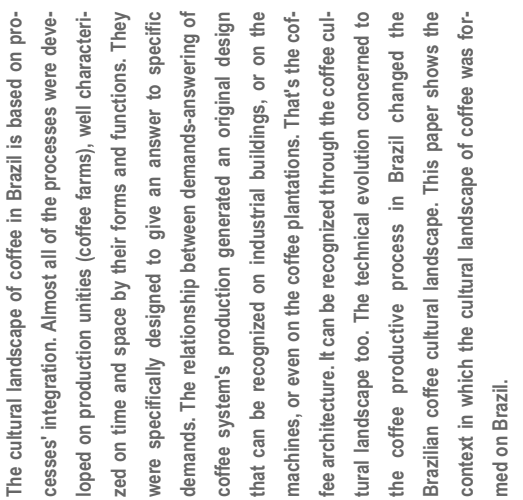

Es un hecho constatable el que existe una fuerte relación entre el desarrollo tecnológico y la evolución de la arquitectura (particularmente la arquitectura de la producción); esto remite a la idea de que la arquitectura del paisaje co-evoluciona como respuesta directa y armónica a los cambios originados en el desarrollo del sistema productivo.

Durante el período en el que la del café fue la principal industria brasileña (de la segunda mitad del siglo XIX hasta mediados del siglo XX), el complejo productivo de las haciendas evolucionó en consonancia con las transformaciones culturales (tecnológicas, sociales, económicas, políticas, etc.) surgidas en la sociedad a lo largo de ese periodo.

1. Argollo Ferrão, A.M. Técnica \& Arquitetura. São Paulo: FAU USP, 1998. Tese de Doutorado. 